\title{
Closed Reduction and Percutaneous Screws Fixation in Tibial Plateau Fractures
}

Omar M. Abdelkareem, Anis M. Shiha, Hussam Eldin M. Elazab, Mohamed Ali Department of orthopedics and traumatology, Sohag University, Egypt

\section{ABSTRACT}

Purpose:To evaluate treatment outcomes of closedreduction and percutaneous screw fixation for tibialplateau fractures.

Methods: 18 men and 4 women aged 21 to 64 (mean, 38.1) years underwent closed reduction and percutaneous screw fixation for closed tibial plateaufractures. According to theSchatzker classification, patients were classifiedinto type $I(n=6)$, type III $(n=10)$, type IV $(n=4)$, andtype V $(n=2)$. Closed reduction was achieved usingmanual ligamentotaxis with traction in extensionunder image intensifier control. Reduction was fixedpercutaneously with cancellous screws $(6.5 \mathrm{~mm})$ andwashers. Functional outcome (pain, walking capacity,extension lag, range of motion, stability and return to daily activity) wasevaluated using the Modified Hospital for Special Surgery Score. A total score of 55 to 60 was considered as excellent, 45 to 54 as good, 35 to 44 as fair, and $<35$ as poor.

Results:Patients were followed up for a mean of 8 (range, 6-12) months. The mean length of hospitalstay was 2 (range, 1-3) days. All the fracture unitedradiographically after a mean of 3 (range, 2.5-3.5)months. Respectively in Schatzker types-I, -III, -IV, and-V fractures, outcomes were excellent in 4, 1, 1, and 0 patients, good in 2, 6, 2, and 0 patients, fair in $0,3,0$, and 1 patients, and poor in $0,0,1$, and 1 patients.

Outcome was satisfactory (good-to-excellent) in 100\%, 70\%, 75\%, and $0 \%$ of the respective fracture typesof patients. The mean Modified-HSS score was 46.2 for all patients; it was 53.3 for type I, 40.3 for typeIII, 45 for type IV, and 36 for type V fractures. One patient had metal failure due to early weight bearing at 5 weeks. No patient had infection or wound dehiscence.

Conclusion:Closed reduction and percutaneous screw fixation for tibial plateau fractures is minimally invasive. It reduces the length of hospitalstay and costs, enables early mobilization with minimal instrumentation, and achieves satisfactory outcomes.

\section{INTRODUCTION}

The lateral side of the knee joint is most commonly injured during road traffic accidents, which results intorn ligaments, sprains, and fractures of one or both condyles. (1) Tibial plateau fractures are intra-articularfractures caused by high-velocity trauma. Theyare usually associated with neurovascular injury,compartment syndrome, compounding of fractures, and crushing of soft tissues. Associated injuries atand around the knee joint are more common andsevere in patients with fracture-dislocation. $\left.{ }^{(\mathbf{1},}{ }^{2}\right)$ The treatment outcomes for tibial plateau fractures are inconsistent. ${ }^{(3)}$ Closed reduction (basedon ligamentotaxis principles) and internal fixation (with percutaneous cancellous screws and washers)avoids the disadvantages of both operative andconservative treatments. However, it is not suitablefor all types of tibial plateau fractures, particularlygrossly comminuted and depressed fractures,Schatzker type-VI fracturesand open fractures. $(\mathbf{4}, \mathbf{5})$ Weevaluated treatment outcomes of closed reduction and percutaneous screw fixation for tibial plateau fractures.

\section{PATIENTS AND METHODS}

Between June 2016 and June 2017, 18 men and 4 women aged 21 to 64 
(mean, 38.1) years underwent closed reduction and percutaneous screwfixation for closed tibial plateau fractures. 14 of them involved the right side.The causes of injury included motor cycle accidents $(\mathrm{n}=10)$, motor car accident $(\mathrm{n}=6)$, fall from a height $(n=4)$, and fall on the ground $(n=2)$. According to theSchatzker classification, patients were classifiedinto type I (lateral split) $(n=6)$, type III(lateral split with depression) $(n=10)$, type IV (medial condyle fracture) $(\mathrm{n}=4)$, andtype $\mathrm{V}$ (bicondylar fracture) $(\mathrm{n}=2)$. Associated injuries included ankle fracture $(n=1)$, tibial spine $(\mathrm{n}=2)$, distal femur $(\mathrm{n}=1)$.

Patients with type II (lateral depression), type VI (fracture extending tothe metaphysis), open fractures, compartment syndrome, or vascularinjury were excluded. This study was approved by the ethics committee of our hospital. Informedconsent was obtained from each patient.

Antero-posterior and lateral radiographs of the knee joint wereobtained. Computed tomography was performed to assess articular depression. The lower limb was rested in above-knee posterior splint.

Patients were operated on as soon as they weremedically fit. The mean delay in surgerywas 2 (range, 1-3) days. Closedreduction was achieved using manual ligamentotaxis with traction in extension under image intensifier control. Both sides of the proximal tibiawere thumped to dislodge the depressed articularfragment.

Reduction was held temporarily withone- or 2-pointed reduction forceps, and then fixedpercutaneously with 2 cancellous screws $(6.5 \mathrm{~mm})$ and washers.

Articular congruency was checked undera $\mathrm{C}$-arm in antero-posterior and lateral views. Thelimb was then immobilized in above-knee cast.

The rehabilitation protocol was standard forall patients. Patients were encouraged to performisometric quadriceps exercises, ankle pump, and toe movements. Analgesia and antibiotics were given.The cast was removed after 4 weeks, and the kneejoint was examined for tenderness, swelling, andinstability. Gradual knee bending and extensionexercises were advised with non-weightbearingcrutch walking for further 4 weeks. Partial and fullweight bearing was allowed at week 8 and week 12 ,respectively. Patients were followed up at 6 and 12 months.

At the final follow up, functional outcome (pain,walking capacity, extension lag, range of motion, stability and return to daily activity) was evaluated using the Modified Hospital for Special Surgery Score (Table). ${ }^{(6)}$ 
TableThe Modified Hospital for Special Surgery Knee Score (HSSKS)

\begin{tabular}{|c|c|c|c|c|c|}
\hline \multirow{6}{*}{ 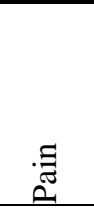 } & Constant, unbearable & 0 & \multirow{6}{*}{ 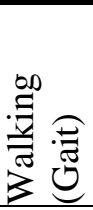 } & Bedridden & 0 \\
\hline & Constant, bearable & 2 & & Uses a wheelchair & 2 \\
\hline & Pain with activities & 4 & & Markedly restricted, uses bilateral support & 4 \\
\hline & Pain at start of activities & 6 & & Moderately restricted, uses one support & 6 \\
\hline & Occasional and slight pain & 8 & & Mildly restricted, limping without support & 8 \\
\hline & None & 10 & & Unrestricted, no limp, no support & 10 \\
\hline \multirow{6}{*}{ 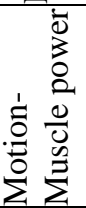 } & Ankylosis with deformity & 0 & \multirow{6}{*}{ 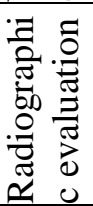 } & Non-union, metal failure, secondary arthritis & 0 \\
\hline & Ankylosis with good functional position & 2 & & Delayed union & 2 \\
\hline & Poor to fair muscle power, flexion $\leq 60^{\circ}$ & 4 & & Varus $>10^{\circ}$, shortening $>2.5 \mathrm{~cm}$ & 4 \\
\hline & Fair to good muscle power, flexion up to $90^{\circ}$ & 6 & & Varus $5^{\circ}-10^{\circ}$, shortening $1-2.5 \mathrm{~cm}$ & 6 \\
\hline & Good to normal muscle power, flexion $\geq 90^{\circ}$ & 8 & & Varus $<5^{\circ}$, shortening $<1 \mathrm{~cm}$ & 8 \\
\hline & Muscle power normal, motion normal & 10 & & Anatomic reduction & 10 \\
\hline \multirow{7}{*}{.0̃ } & Retired pre-injury & & \multicolumn{2}{|c|}{ Employed pre-injury } & \\
\hline & Completely dependent & & \multicolumn{2}{|c|}{ Retired } & 0 \\
\hline & Partially dependent & & \multicolumn{2}{|c|}{ Part-time/ light duty } & 2 \\
\hline & Independent, limited housework & & \multicolumn{2}{|c|}{ Changed jobs } & 4 \\
\hline & Do most housework, shops freely & & \multicolumn{2}{|c|}{ Altered job description } & 6 \\
\hline & Little restriction, walk on feet & & \multicolumn{2}{|c|}{ Returned to work } & 8 \\
\hline & Normal activities & & \multicolumn{2}{|c|}{ Returned to full work } & 10 \\
\hline 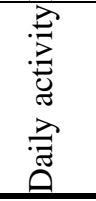 & $\begin{array}{l}\text { Shoes \& socks: } \\
\text { Unable } \\
\text { With difficulty } \\
\text { With ease }\end{array}$ & $\begin{array}{l}0 \\
3 \\
5\end{array}$ & \multicolumn{2}{|c|}{$\begin{array}{l}\text { Stairs: } \\
\text { Unable } \\
\text { One at a time } \\
\text { Normal }\end{array}$} & $\begin{array}{l}0 \\
2 \\
4\end{array}$ \\
\hline
\end{tabular}

A total score of 55 to 60 was considered as excellent, 45 to 54 as good, 35 to 44 as fair, and $<35$ as poor.

\section{RESULTS}

Patients were followed up for a mean of 8 (range, 6-12) months. The mean length of hospitalstay was 2 (range, 1-3) days. All the fracture unitedradiographically after a mean of 3 (range, 2.5-3.5)months. Respectively in Schatzker types-I, -III, -IV, and-V fractures, outcomes were excellent in $4,1,1$, and 0 patients, good in 2, 6, 2, and 0 patients, fair in $0,3,0$, and 1 patients, and poor in $0,0,1$, and 1 patients.Outcome was satisfactory (good-to-excellent) in 100\%, 70\%, 75\%, and $0 \%$ of the respective fracture typesof patients. The mean Modified-HSS score was 46.2 for all patients; it was 53.3 for type I, 40.3 for typeIII, 45 for type IV, and 36 for type V fractures. One patient had metal failure due to early weight bearing at 5 weeks. No patient had infection or wound dehiscence.

\section{DISCUSSION}

Tibial plateau fractures are difficult to treat becauseof their intra-articular nature, cancellous bone involvement, and proximity to a major weight bearingjoint. The aim of the surgical treatment of tibial plateau fractures is to restore normal knee function. This is accomplished by anatomically restoring the articular surfaces of the tibial condyles, maintaining the mechanical axis, restoring ligamentous stability.

The limitations of conservative treatment are inadequate reduction of the articular surface, ineffective limbalignment control, and prolonged hospitalization andrecumbency, which causes quadriceps atrophy andrange of movement restriction. Operative treatment restores articular congruity, axial alignment, andjoint stability, and enables early mobilization whiledecreasing the risk of posttraumatic arthritis.

Nonetheless, operative treatment compromises softtissues, devascularises bone fragments, and may becomplicated by infection, implant failure, and wound dehiscence. Thus, it is not indicated for all types oftibial plateau fractures.

Closed reduction and percutaneous screw fixationis minimally invasive and thus reduces the length of hospital 
stay and costs ${ }^{(5)}$. It is indicated in patientswith a large peripheral fragment (i.e. Schatzkertype-I, -III, and -IV fractures). In our study, patients with Schatzker type-V (bicondylar) fractures were indirectly reduced with manual ligamentotaxis. Thearticular condyle was then reduced to the shaft andfixed with screws. Such patients achieved relativelypoor outcome and should have been treated with openreduction and internal fixation with plate and screw.

Irrespective of treatment modality, earlymobilization (no later than 4 weeks) is essential to prevent knee stiffness (2). Impacted articular fragmentscannot be dislodged by traction or manipulation alone as there is no soft-tissue attachment ${ }^{(2)}$.In our study, patients with depressed fractures (type II)were excluded, as it is

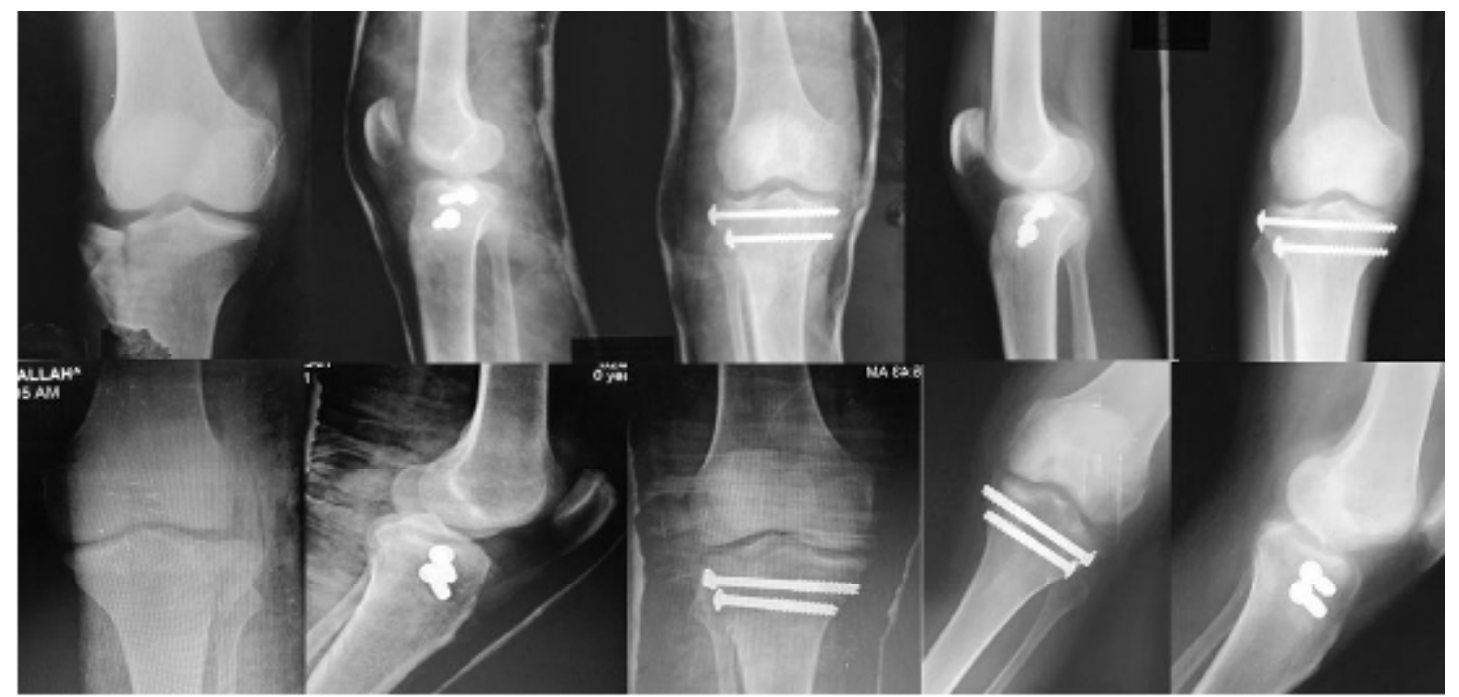

Figure Schatzker (a) type-III and (b) type-I tibial plateau fractures fixed with percutaneous cancellous screws

difficult to achieve articular congruency by traction or manipulation. ${ }^{(7,8)}$

In 22 patients with closed tibial plateau fractures treatedwith percutaneous cancellous screws and washers, The mean Modified-HSS score was 46.2 for all patients (range, 59-30) after a mean follow up of 8months; outcome was excellent in $32 \%$, good in $48 \%$, and unacceptable in $20 \%$ of patients; unacceptable outcomes were likely due to minimal (rather than rigid) fixation for comminutedor depressed fractures. In addition, a few patients had loss of knee range of motion owing to delayedknee mobilization. ${ }^{(\mathbf{9}, 10)}$

Outcome was satisfactory (good-toexcellent) in $100 \%, 70 \%, 75 \%$, and $0 \%$ of the respective fracture typesof patients. The mean Modified-HSS score was 46.2 for all patients; it was 53.3 for type I, 40.3 for typeIII, 45 for type IV, and 36 for type V fractures.
In our study, manualligamentotaxis successfully reduced fractures witha peripheral fragment, whereas a femoral distractorsuccessfully reduced fractures with comminution using an indirect technique. ${ }^{(11,12)}$ Guarded thumpingon both sides of proximal tibia helped dislodge the depressed fragment. The depressed fragment can beelevated using an arthroscopy, which also enablesdirect visualization of the articular congruency.

Arthroscopic reduction is superior to closed reduction and broadens the indications of minimally invasivepercutaneous fixation. Nonetheless, it needs expertise and infrastructure. Percutaneous cancellous screwfixation with arthroscopic elevation of the depressed articular 
fragment is a favorable treatment modalityfor tibial plateau fractures. ${ }^{(13)}$

\section{REFERENCES}

1. Hohl M. Articular fractures of the proximal tibial. In: Evarts CM, editor. Surgery of the musculoskeletal system. New York: Churchill-Livingstone; 1993:3471-97.

2. Schatzker J. Fracture of the tibial plateau. In: Schatzker J, Tile M, editors. The rationale of operative fracture care. Berlin: Springer-Verlag; 1987:279-95.

3. Stevens DG, Beharry R, McKee MD, Waddall JP, Schemitsch EH. The longterm functional outcome of operatively treated tibial plateau fractures. J Orthop Trauma 2001;15:312-20.

4. Sangwan SS, Siwach RC, Singh R, Mittal R. Minimal invasive osteosynthesis: a biological approach in treatment of tibial plateau fractures. Indian J Orthop 2002;36:246-50.

5. Shete K, Sancheti P, Kamdar R. Role of Esmarch bandage and percuteneous cannulated cancellous screws in tibial condylar fracture. Indian $\mathbf{J}$ Orthop 2006;40:173-6.

6. Weigel DP, Marsh JL. High-energy fractures of the tibial plateau. Knee function after longer follow-up. J Bone Joint Surg Am 2002;84:1541-51.
7. De Mourgues G, Chaix D. Treatment of fracture of the tibial plateau [in French]. Rev Chir Orthop Reparatrice Appar Mot 1964;50:103-22.

8. Apley AG. Fractures of the tibial plateau. Orthop Clin North Am 1979;10:61-74.

9. Mathur H, Acharya S, Nijhawan VK, Mandal SP. Operative results of closed tibial plateau fractures. Indian J Orthop 2005;39:108-12.

10.Lobenhoffer P, Schulze M, Gerich T, Lattermann C, Tscherne $\mathrm{H}$. Closed reduction/percutaneous fixation of tibial plateau fractures: arthroscopic versus fluoroscopic control of reduction. J Orthop Trauma 1999;13:426-31.

11. Mast J, Jakob R, Ganz R. Reduction with distraction. In: Mast J, Jakob R, Ganz R, editors. Planning and reduction technique in fracture surgery. Berlin: Springer-Verlag; 1989:130-42.

12. Koval KJ, Sanders R, Borrelli J, Helfet $\mathrm{D}$, DiPasquale T, Mast JW. Indirect reduction and percutaneous screw fixation of displaced tibial plateau fractures. $\mathbf{J}$ Orthop Trauma 1992;6:340-6.

13.Keogh P, Kelly C, Cashman WF, McGuinness AJ, O'Rourke SK. Percutaneous screw fixation of tibial plateau fractures. Injury 1992;23:3879. 